\title{
CONTRADIÇÕES E DISPUTAS NA POLÍTICA DE CONVENIAMENTO ENTRE ESTADO E MOVIMENTOS POPULARES NOS ANOS 2000: 0 CASO HELIÓPOLIS
}

\author{
Hugo Fanton Ribeiro da Silva ${ }^{a}$
}

é doutor em Ciência Política pelo Instituto de Filosofia e Ciências Humanas da Universidade Estadual de Campinas (IFCH/Unicamp), e mestre em Saúde Pública pela Faculdade de Saúde Pública da Universidade de São Paulo (FSP/USP). Campinas, São Paulo, SP, Brasil.

E-mail:<hfanton@gmail.com>

Orcid: 0000-0001-9202-9131

http://dx.doi.org/10.1590/0102-149180/105

\section{Introdução}

A política brasileira no contexto pós-constituinte, no que se refere aos processos de elaboração e execução de políticas públicas em diferentes âmbitos da administração pública, bem como à sua relação com a atuação dos movimentos sociais, é caracterizada por contradições que remontam à disputa entre diferentes projetos políticos de Estado e sociedade, com dimensões econômicas, sociais e ideológicas. Projeto político é aqui concebido como conjunto "de crenças, interesses, concepções de mundo, representações do que deve ser a vida em sociedade, que orientam a ação política dos diferentes sujeitos" (Dagnino, Olvera e Panfichi, 2006, p. 38), e sua combinação com adjetivações como "neoliberal" e "democrático-popular" define quais interesses, simbologias e programas determinado projeto reúne em torno de si.

Ao longo dos anos 1990, os setores empresariais avançaram na administração pública orientados pelo projeto neoliberal, participando da gestão social por meio das "empresas parceiras", que se responsabilizam pela oferta de serviços. 
Tal processo foi fundamentado na concepção de um "Estado Social", caracterizado por práticas que aproximam política pública e mercado, extraindo deste os critérios que legitimam "os próprios serviços e os gestores" (Bresser-Pereira, 2010, p. 10). Na medida em que tais forças neoliberais encontram no Brasil um campo de disputa conformado ao longo dos anos 1970-80 a partir da noção de extensão de direitos e da participação social, o denominado projeto democrático-popular, houve um esforço de interlocução do neoliberalismo com o discurso participativo e democratizante. Nesse contexto, participação, cidadania e sociedade civil, categorias centrais no projeto democrático-popular, foram progressivamente apropriadas e redefinidas pelo projeto neoliberal, que se vale de um referencial comum para implementar políticas antagônicas àquelas a que os termos anteriormente se referiam.

Trata-se de um processo histórico de "confluência per150 versa" entre dois projetos distintos: como forma de legitimação da política, são mobilizadas "as mesmas palavras e referências, mas seu significado já é outro, ainda que essas diferenças não se explicitem com clareza, o que precisamente torna perversa a confluência” (Dagnino, Olvera e Panfichi, 2006, p. 55). Os deslocamentos de sentido obscurecem o conflito presente entre dois projetos que, apesar de apontarem para direções antagônicas, se valem de um referencial comum na análise e definição das práticas sociais e políticas.

São expressões disso a progressiva transformação da "sociedade civil movimentista" em direção ao "marco discursivo do "terceiro setor" (Feltran, 2008, p. 40) e "a adoção de uma perspectiva privatista e individualista" de participação, de forma a "substituir e redefinir o significado coletivo" a que o termo remete no projeto democrático-popular (Dagnino, 2004, pp. 102-103). Opera-se ainda uma "conexão entre cidadania e mercado", de modo que "tornar-se 
cidadão passa a significar a integração individual ao mercado, como consumidor e como produtor", o que leva a uma "diluição precisamente daquilo que constitui o núcleo da concepção de cidadania, a ideia de direitos universais" (Dagnino, Olvera e Panfichi., 2006, p. 56).

É igualmente constitutiva desse debate a "sustentabilidade" dos movimentos e associações. As organizações que compõem a sociedade civil se tornam "parceiras" na gestão do espaço social e assim legitimam suas ações, com atividades garantidas por "recursos públicos e privados que possibilitem a prestação de serviços a seu público-alvo" (SchererWarren, 2006, p. 113). Disto decorre a necessidade de empreender um esforço analítico que exponha e discuta "as diferenças, os conflitos e a disputa entre os projetos políticos em presença" (Dagnino, Olvera e Panfichi, 2006, pp. 58-60).

É nesse sentido que este artigo tem por objetivo analisar significados do financiamento público de atividades político-sociais e seu impacto na ação e no projeto político dos movimentos populares, com enfoque na relação entre Estado e sociedade pela forma convênio nas áreas de assistência social e educação ao longo dos anos 2000, durante os governos Lula e Dilma (PT: 2003-2016). Nesse período, assim como nos anos 1990, houve grande expansão de serviços não exclusivos do Estado, e este texto discute os modos como os embates nacionais acerca das políticas sociais e seus resultados em termos de política pública influenciaram formas de atuação local, bem como os conflitos e disputas no interior do movimento popular e sua autonomia. A análise, a partir de um estudo de caso e da evolução da política nacional nas áreas em foco, perpassará os significados que assume a política de celebração de convênios para os movimentos populares, os significados de cidadania e participação nesse contexto, e os valores, concepções e interesses relacionados à "autonomia" do movimento social que estabelece relações econômicas com o Estado, para discutir as contradições e 
disputas relativas a essa forma específica de relação entre sociedade civil e Poder Público. Por fim, a discussão é contextualizada nacionalmente, pois a intensificação na celebração de convênios não é fato isolado, mas remonta a disputas pela construção democrática do Brasil dos anos 2000.

\section{Materiais e métodos}

Para atingir os objetivos desta pesquisa, foi realizado um estudo de caso em Heliópolis, maior favela de São Paulo/ SP, com população estimada em cerca de duzentas mil pessoas e uma área de aproximadamente 1,2 milhão de metros quadrados, pertencente à Companhia Metropolitana de Habitação (Cohab). Em 2016, a renda familiar média per capita local era de $\mathrm{R} \$ 479,85$, o que correspondia a $54,52 \%$ de um salário mínimo. A ocupação do território teve início em 1968, com a construção do Hospital Heliópolis e do Posto de Assistência Médica (PAM). Entre 1971-72, a 152 Prefeitura transfere para a área 153 famílias, vindas da favela de Vila Prudente. No entorno de seus alojamentos provisórios, do Hospital e de minas d'água, novos moradores intensificam a ocupação ao longo dos anos 1970-80 (Sampaio, 1991).

O processo organizativo local teve início com uma Comissão de Moradores, criada em 1978 para lutar por água, luz e melhores condições de vida. Em 1987, a comissão se tornou União de Núcleos, Associações e Sociedades dos Moradores de Heliópolis e Região (UNAS), que se consolidou como principal associação de moradores local, com atividades que perpassam diferentes áreas, tais como habitação, educação e assistência social. Em 2017, a UNAS atendeu, diretamente, doze mil pessoas pelos mais de cinquenta projetos sociais que desenvolve.

Para produção do material empírico desta pesquisa, optou-se por instrumentos e técnicas do método etnográfico, entendido enquanto "modo de acercamento e apreensão" 
de dada realidade. No trabalho de campo, houve observação participante de reuniões e espaços de organização e mobilização dos sujeitos da pesquisa, com registro em diário e coleta de material documental. As informações foram utilizadas na construção de uma descrição densa da realidade (Geertz, 1978) e na fundamentação de entrevistas semiestruturadas (Ruquoy, 1997). Os nomes dos sujeitos da pesquisa estão mantidos em sigilo (atribuiu-se aleatoriamente nomes fictícios às pessoas para facilitar a leitura).

Entre junho e setembro de 2010, foram realizadas 39 visitas e entrevistadas 79 pessoas, dentre lideranças populares e gestores públicos. Deu-se início a novo trabalho de campo entre novembro de 2013 e maio de 2014, com 57 visitas e redação em diário. Com base neste material, foi possível analisar que demandas os sujeitos apresentam, como atuam e qual sua relação com as disputas políticas existentes. A construção do material empírico buscou reorganizar "informações ainda dispersas, indícios soltos, num novo arranjo", que carrega consigo uma apreensão da realidade "mais geral do que a explicação nativa", e mais densa "que o esquema teórico inicial do pesquisador". A descrição foi feita a partir da relação entre falas e práticas observadas, e do entrejogo entre ambas tornou-se possível construir a análise, fundamentada na discussão teórica (Magnani, 2002, p. 17).

Adotou-se um caminhar que combina análise estrutural com a fenomenológica, pressupondo-se uma compatibilidade entre elas, ou seja, que parte da inteligibilidade das práticas microssociais é explicada pelo contexto histórico em que se inserem. A descrição do caso foi articulada com a das políticas nacionais do setor educação nos governos Lula-Dilma, assente em fontes secundárias advindas da literatura. Entende-se a importância do caso pela "amplitude das incidências estruturais que nele se denunciam", assim como a "multiplicidade e profundidade das interacções que 
o constituem" (Santos, 1983, p. 12). Desse modo, a discussão combina os significados atribuídos ao convênio pelas lideranças populares no material etnográfico, com aqueles expostos por autores na literatura sobre o tema, na busca por uma nova interpretação do objeto de pesquisa.

\section{Resultados e discussão}

Heliópolis, 40 anos de lutas, conquistas e transformações

Heliópolis teve progressivo aumento populacional nos anos 1970-80, resultante de autoconstrução habitacional por famílias sem-teto. Além das ocupações espontâneas, "outro tipo de ocupação, a grilagem, começava a aparecer”. Isso levou a um "clima de violência, com contínuas disputas entre invasores e grileiros”, e à reação do poder público, que impetrou "uma série de reintegrações de posse", intensificando a luta pela terra. "Data daí o início da organização 154 da população moradora, que nessa ocasião já estava começando a reivindicar serviços de água e luz" pela Comissão de Moradores (Sampaio, 1991, pp. 31-34).

A Comissão era composta por "núcleos" distribuídos por Heliópolis, e por meio dela foi organizada a luta pela posse da terra e por melhorias nas condições de vida. Houve constante pressão sobre a Prefeitura por regularização fundiária e serviços de água e luz, em diferentes gestões, como as de Reynaldo de Barros (PDS: 1979-1983) e Mário Covas (PSDB: 1983-1985). No governo Jânio Quadros (PTB: 1986-1988), as lideranças decidem ocupar uma casa da Assistência Social da Prefeitura em Heliópolis, em 1986, para reivindicar moradia e infraestrutura.

Naquele ano, a gestão coloca a legalização da Comissão como condição para negociação referente ao processo de urbanização. "A gente foi obrigado a fundar a UNAS". À época, havia por parte das lideranças um medo de perda de combatividade em decorrência da legalização. Alguns 
temiam "ser processado por conta dessa entidade", enquanto outros defendiam a formalização da associação (Lia, da diretoria da UNAS). Pela diversificação das atividades em Heliópolis e conquistas materiais, Ester acredita que as mudanças foram positivas, pois resultaram em conquistas de "coisas muito concretas", como moradia e saneamento: "A gente começa a abrir projetos, buscar a prefeitura" (Ester, diretora da UNAS).

A relação entre UNAS e poder público foi tensa durante todo o mandato de Jânio Quadros, em razão da ameaça constante de remoção e dificuldades no andamento do Plano Habitacional, que previa regularização fundiária e construção de habitação de interesse social. Em resposta a isso, a UNAS realizou, ao longo de 1987, assembleias e manifestações, em articulação com parlamentares ligados ao Partido dos Trabalhadores (PT) e integrantes do Movimento Unificado de Favelas (MUF), que reunia centenas de favelas de São Paulo.

Com a eleição da prefeita Luiza Erundina (PT: 19891992), uma candidata historicamente comprometida com um projeto participativo e de extensão de direitos, é colocada para a UNAS uma novidade quanto à relação com o poder público: pela primeira vez tem como interlocutor uma gestão comprometida com o mesmo projeto que reivindicam, o democrático-popular. Erundina promoveu novas formas de administração, com conveniamentos na construção habitacional por "autogestão", e na assistência social e educação, pelo início do Movimento de Alfabetização de Adultos (MOVA). Para Heliópolis, foi elaborado um plano de habitação que atendeu 613 famílias por mutirão, 178 por empreiteira e 6 mil por urbanização (Negrelos, 1998).

A gestão seguinte, no entanto, traz uma inflexão neoliberal para a conjuntura política do município, e isso impacta diretamente Heliópolis. No governo Paulo Maluf (PPB: 1993-1996, que passou a se chamar PP em 2003), não se deu continuidade às políticas sociais da antecessora. Além 
de eliminar os mecanismos de participação, a gestão paralisa todas as obras de infraestrutura e construção habitacional, e apoia os mais de setenta processos de reintegração de posse em favor da Cohab. Em Heliópolis, o momento de maior tensão aconteceu em dezembro de 1993, quando um setor da comunidade - a Quadra H - foi cercado pela Tropa de Choque para cumprimento de ordem de despejo. "O Maluf veio onde fica hoje o Terminal Sacomã, a ROTA ficou do lado do Hospital Heliópolis, mas fizemos cordão humano em toda área, e barricadas na rua Delamare, todo o mundo ajudava", explica Pedro. A ação durou muitas horas, havia cobertura midiática e presença de parlamentares e padres em apoio à comunidade, "alertando que seria um massacre. Nesse momento era na Quadra H porque não dava para tirar de uma vez todo mundo, então resistíamos juntos em todas as áreas, porque se mexesse em uma, tirariam todas" (Pedro, diretor da UNAS). Após algumas horas de confronto com a 156 polícia, uma juíza suspendeu a reintegração.

Este foi o último grande enfrentamento da UNAS frente ao poder público municipal. Como parte central da nova tática adotada, a UNAS expande os convênios ao longo dos anos 1990 em diferentes áreas da atuação social. Em 1998, época da administração Celso Pitta (PPB: 1997-2000), a entidade estabelece convênio com a Secretaria Municipal de Assistência Social, o "Parceiros da Criança", que até 2016 possibilitou a construção de ações na área. Nesse mesmo ano, por uma articulação com o então deputado federal Aloísio Mercadante (PT-SP), é criado o projeto "Se Liga Galera”, de formação de adolescentes e jovens de Heliópolis. Há ainda o programa Alfabetização Solidária, implantado durante o governo Fernando Henrique Cardoso (PSDB: 1995-2002), que chega à comunidade pela celebração de um convênio. Destaca-se também a municipalização das creches no Brasil, o que permitirá à UNAS captar recursos para atendimento direto da população. 
Nesse âmbito, é selada uma parceria que perdura até hoje (2017) com a Action Aid, instituição inglesa que "nos ajudou a montar a creche. Veio trazer formação política e estabelecer vínculos solidários. É fortalecimento institucional e luta por políticas públicas" (Leonardo, diretor da UNAS). Nos anos 2000, durante o governo municipal de Marta Suplicy (PT: 2001-2004) e nos governos federais de Lula (PT: 2003-2010) e Dilma (PT: 2011-2014), a educação e a assistência social se tornam as principais áreas de atuação da UNAS.

A lógica de conveniamento para provisão de serviços públicos se intensificou no século XXI. Em 2001, a UNAS convenia seu primeiro Centro de Educação Infantil (CEI) e, ao longo da década, outros equipamentos serão assumidos pela entidade, tais como os Centros para Criança e Adolescente (CCAs). A associação também mantém atuação na lógica movimentista e voltada à participação, conforme horizonte de luta dos anos 1980: a militância é eleita para ocupar o Conselho Municipal em Defesa da Criança e do Adolescente, conselhos de saúde, e são formados novos movimentos para organizar e mobilizar a população na luta por direitos, com destaque para o Movimento de Mulheres de Heliópolis e Região, Movimento LGBT, Fórum de Juventude e o Movimento Sem Teto de Heliópolis e Região.

De acordo com Cobra (2007), em 2005, a UNAS já possuía número significativo de parcerias e convênios se comparado ao final dos anos 1990: eram cinco CEIs (uma delas em convênio com o estado de São Paulo), um Telecentro, uma Lavanderia Comunitária e a continuidade de programas iniciados nos anos 1990, dentre outros. O processo de articulação política fez que a associação chegasse, na metade de 2016, a 16 CEIs, com capacidade de atendimento de 2.685 crianças da comunidade; 11 CCAs, que atendiam 1.560 crianças e adolescentes; um projeto de Medida Socioeducativa (MSEs), que atendia 210 adolescentes; um 
Serviço de Assistência Social a Família (SASF), para mil famílias; e um Núcleo de Proteção Social e Apoio Psicológico (NPJ), com 120 beneficiários, dentre outros serviços.

\section{Tabela 1}

Evolução histórica no número de convênios e parcerias, com base nos relatórios anuais de gestão da UNAS

\begin{tabular}{|c|c|c|c|c|c|c|}
\hline Ano & CEls & Atendidos & CCAs & Atendidos & Outros & Atendidos \\
\hline 2001 & 1 & 100 & 1 & 70 & 8 & 1800 \\
\hline 2005 & 5 & 600 & 6 & 550 & 15 & 3550 \\
\hline 2012 & 10 & 1276 & 7 & 670 & 29 & 6685 \\
\hline 2013 & 12 & 1724 & 11 & 1320 & 34 & 8073 \\
\hline 2014 & 13 & 2010 & 11 & 1320 & 34 & 8169 \\
\hline 2015 & 14 & 2254 & 11 & 1320 & 36 & 8272 \\
\hline 2016 & 16 & 2685 & 11 & 1560 & 36 & 8653 \\
\hline
\end{tabular}

Fonte: elaboração própria.

A visão acerca da política de celebração de convênios é heterogênea na UNAS. No dizer de Leonardo, desde os anos 1990 a relação com o poder público tem se transformado, pois "a conjuntura mudou. A gente faz agora o movimento mais de lobby". Isto decorre de "uma cadeia de oportunidades". O enfrentamento direto, no seu entender, traz desgaste, pois "quem tem força são os caras, se os caras quiserem vir pra cima, não tem como”, referindo-se ao Estado. Para Leonardo, dificilmente um movimento tem mais força que o poder público, pois ainda que faça ocupações para deslegitimar uma gestão, muitas vezes "se queima com a própria base" (Leonardo, diretor da UNAS).

Marcinha explica que, independentemente de quem está à frente da prefeitura, não há mais confronto, enfrentamento direto, pois "mudou nossa estratégia, a gente vai atrás do poder público, não adianta ir lá e bater, fazer arruaça, porque muitas vezes não resolve. Tem que ir mais no diálogo" (Marcinha, diretora da UNAS). Já no dizer de Gustavo, a UNAS não "pode depender do poder público a vida inteira", é preciso trabalhar para "caminhar com as 
próprias pernas. E cada vez mais estamos partindo para isso". Ele enfatiza que a associação nunca foi "para-choque do governo", pois "a sociedade civil pode ter um papel determinante na formação do jovem" e da comunidade, cumprindo o papel de "cobrar efetivamente o direito às políticas públicas do município, do estado e da União", que devem assumir a responsabilidade. "É quem detém o poder" (Gustavo, diretor da UNAS).

Por isso, há necessidade de se pensar na "sustentabilidade" da associação, para que não se torne "prestador de serviço. A UNAS tem quinhentos funcionários, mas não tem patrimônio nenhum, isso é uma coisa que a gente está trabalhando para mudar", o que significa construir "projetos" que deem sustento para a entidade. "Na verdade, o governo quer terceirizar o serviço, não quer organizar o movimento", o que aponta para conflitos e contradições decorrentes dessa forma de relação entre movimento e Poder Público. "Na área da moradia, mutirão, quem ganha mesmo é a assessoria, os arquitetos de classe média. Outro jeito que os movimentos vivem é às custas do parlamentar, o cara tem o mandato e aí acaba a discussão política”. Assim, sacrifica-se também a autonomia do movimento. "A não ser que coincida, que o mandato coincida com o movimento" (Leonardo, diretor da UNAS).

Já Roberto afirma que, ao chegar a Heliópolis para trabalhar como diretor da escola Campos Salles, em 1995, as lideranças tinham a visão de que era "o poder público que tem que ser acionado e resolver problema. E não é assim”. Hoje, a "ONG sabe" que "todos são responsáveis" e sua "principal tarefa" é "fazer articulações" para a efetivação dos direitos. Ele lembra que Heliópolis era considerada uma das comunidades mais organizadas de São Paulo, "mas ainda dentro daquela esquerda radical. E um povo que não tinha autonomia diante dos políticos, que vivia de gabinetes". Hoje, "a UNAS tem um poder muito grande na cidade", 
devido "às articulações" e força de cobrar o poder público. "E esse cobrar não significa brigar, significa fazer junto" (Roberto, diretor da UNAS).

Tadeu considera imprescindível que o povo se organize e administre recursos, o que traz "dignidade, isso é fundamental na política". Ressalta que "não existe autonomia de um povo sem o econômico", o que significa "aprender a administrar, ser capaz de ter projeto", pois isso é "fundamental para que cresça uma autonomia”. Para ele, o Estado tem de ser um "grande regulador de políticas", sem deixar de lado "seu papel de Estado", mas que seja democratizado a ponto de a sociedade ter condições de participar politicamente pelos conselhos e, ao mesmo tempo, tenha condições de administrar verba, pois é preciso "que o dinheiro volte". Assim, administrar uma creche conveniada, ao contrário de tornar a associação "para-choque do governo" por assumir papel que seria do Estado - como criticavam "alguns compa160 nheiros" quando foi assinado o primeiro convênio -, significaria a volta de um "dinheiro que é nosso", para um povo que saiba administrar recursos e, com isso, possa tornar a educação e o Estado mais democráticos (Tadeu, diretor da UNAS).

Outra questão emerge nas palavras de uma diretora da UNAS: "falta liderança político-social. Projeto tem, mas é tudo funcionário, empregado, querem dinheiro, não fazem atividades nos fins de semana para reunir o povo". Assim, a possibilidade de relação de clientela entre os partícipes está presente e sob o risco de preponderar nas parcerias. A alternativa é lutar para que "a gente inverta a pauta" e lute "para virar política pública”.

A isso está atrelada uma formação política que leve à formulação teórica as questões vivenciadas pela militância no dia a dia. "A Marilena Chauí dizia que não tem que tapar buraco, tem que conceituar. Nós fazemos os dois, porque tem a vida das pessoas, e por isso ficam chamando a gente 
de assistencialista. Mas não, a gente tapa buraco e conceitua" (Fátima, diretora da UNAS). Lia acrescenta que "quando fazemos com o coletivo, as coisas mudam". Os riscos colocados sempre foram muito grandes, e já resultaram inclusive em morte de jovem militante da comunidade. "Era muito difícil a luta, foi assassinado na nossa frente. O que pudemos fazer foi catar no colo, e perdemos jovem que estava na luta, foi jovem batalhador. O que quero falar é que continuem com essa força, se articulem, discutam entre vocês a garantia de direitos" (Lia, diretora da UNAS).

O acesso a convênios remonta tanto à força política da UNAS quanto às mudanças conjunturais. Há diferentes visões, com ênfases que ora recaem na descrição do conveniamento como forma de "assumir um papel Estado", e ora o reafirma como construção de força na luta por direitos. Nesse âmbito, os conceitos de autonomia e cidadania ganham centralidade, pois perpassam os conflitos relacionados com essa forma específica de relação entre sociedade civil e Poder Público. A intensificação na celebração de convênios não é fato isolado em Heliópolis, de modo que é preciso analisar quais significados tal política assume para lideranças de uma associação conformada historicamente como integrante do campo democrático-popular, bem como as implicações no projeto político norteador de suas ações.

\section{Financiamento e autonomia}

O movimento social em Heliópolis foi impulsionado pela busca por redefinir a política a partir da extensão dos espaços de atuação e interlocução com o poder público, cuja democratização significa a incorporação de grupos antes marginalizados da organização da vida social no processo político decisório. Inicialmente, o processo organizativo envolvendo instrumento partidário (PT) e movimento popular (MUF) levou a um primeiro reposicionamento e redefinição de campos de luta naquele território: o grupo 
formado pelo enfrentamento a diferentes mecanismos de exclusão social estabelece objetivos que extrapolam o território, em uma construção de força política atuante na cidade e no país.

A UNAS compôs um processo de luta por novo projeto de país, o democrático-popular, que tinha como elementos centrais as noções de participação, cidadania e sociedade civil, em Heliópolis materializadas pela defesa da autogestão na produção habitacional como forma de efetivação do direito à moradia. Cabe destaque à referência, nas falas expostas, à importância da conquista de "autonomia" e à necessidade de "caminhar com as próprias pernas". Esses são elementos definidores de "cidadania" e "participação" no projeto democrático-popular originário nos anos 1970-80, e nas inflexões vividas nas décadas subsequentes.

Como aponta Dagnino (2005), o projeto democrático-popular estabelece como horizonte norteador dois rompimentos históricos que recolocam a cidadania em outros termos na disputa política: i) busca pela superação da "cidadania regulada", restrita a trabalhadores do setor formal (Santos, 1979); ii) busca pela superação da "cidadania concedida", mediada pelas relações de poder e exercida enquanto dádiva ou favor (Sales, 1994). A luta pela cidadania ao longo dos anos 1970-80 - em Heliópolis expressa pelos embates frente aos grileiros, pela criação da Comissão de Moradores, posterior fundação da UNAS e extensão das mobilizações para além da posse da terra - apresenta-se como um projeto de "nova sociabilidade". Trata-se de um projeto político em que cidadania e participação são articuladas e afirmadas enquanto relações sociais igualitárias e necessidade de novas regras de integração social, que impliquem o reconhecimento do outro, a legitimação de direitos e a consolidação de uma dimensão pública da sociabilidade (Dagnino, 2005). 
Além disso, no projeto democrático popular, a participação direta dos movimentos sociais nas decisões de Estado se configura como um dos "mais cruciais aspectos na redefinição de cidadania”, pois nela reside um potencial de transformação radical na estrutura de poder (Dagnino, 2005, p. 8). Em Heliópolis, estavam presentes nos anos 1980 os vários elementos que estabelecem a relação entre a redefinição de cidadania e a participação: ser cidadão significa participar e se tornar sujeito político com possibilidade de definir as formas de organização de vida em sociedade.

No entanto, o avanço das forças neoliberais nos anos 1990 promoveu uma disputa pelo significado dos termos "sociedade civil", "cidadania" e "participação", o que resultou em ambiguidades conceituais e práticas, de modo que os processos participativos em curso se tornariam campo de disputa entre as forças políticas atuantes na sociedade, especialmente "em nível local". A UNAS, em luta por autonomia através do financiamento de suas atividades, pela participação e criação de canais de diálogo com o poder público (elementos presentes na relação com os governos municipais), entra em disputa ideológica, política, social e econômica pelos significados do projeto político que defende ante forças ligadas ao mercado e atuantes no interior do Estado (Dagnino, 2005; 2006).

Quando observamos as transformações por que passa a UNAS e os novos dilemas enfrentados nos anos $1990 \mathrm{e}$ 2000, tal disputa ganha expressão objetiva na luta por autonomia, categoria que sintetiza seus objetivos políticos. A linguagem do direito e a reivindicação de uma comunidade livre traduzem em termos políticos o objetivo de "não ser para-choque do governo", "não ser manipulado por padre ou parlamentar", mostrar que "a sociedade civil pode ter um papel determinante" na efetivação do direito e na cobrança do Estado para que assuma suas responsabilidades, pois "é quem detém o poder". Cotidianamente, combinam-se 
formulações que dão ênfase à responsabilidade individual na ação solidária, de caráter filantrópico, motivada por um dever moral ou mercadológico, com aquelas que buscam "fortalecer" a "sociedade civil" como espaço de luta e efetivação de direitos.

O crescimento dos convênios no decorrer dos anos 2000 ampliou significativamente as possibilidades de incidência da UNAS, que chegou ao final de 2016 com cerca de oitocentos "funcionários". Mas essa maior possibilidade também foi acompanhada por uma nova conformação política, a que o próprio uso do termo "funcionário" em contraposição ao "militante" remete: o projeto que orienta sua ação se torna campo de disputa, e da relação conflituosa com o projeto antagônico emergem novas concepções e objetivos de luta, em uma dinâmica que perpassa a sociedade como um todo.

Ressalta-se que há, em uma mesma política pública, uma combinação de diferentes interesses, e isso foi intensificado 164 ao longo dos anos 2000. As palavras de Lia trazem elementos que conformam o campo democrático-popular: a mudança social advém de uma atuação coletiva, e na coletividade organizada reside a possibilidade de transformação. A vontade não basta, e o risco colocado é, inclusive, de eliminação pelo inimigo: "o que pudemos fazer foi catar no colo". A saída é "continuar com essa força", orientada pelo projeto político de "ser escutado", com a "garantia de direitos". De um lado, está colocada uma perspectiva que entende a UNAS como um posto de trabalho, parte integrante do mercado, um efeito direto do desenvolvimento institucional fundamentado na política de conveniamento. De outro, a reafirmação de sua dimensão associativa, da necessidade de "reunir o povo" e "discutir a garantia de direitos". A contraposição entre "tapar buraco" e "conceituar" é outra expressão desse processo, em uma concepção de que o "fortalecimento da comunidade" tem relação direta com a formação ideológica, com os princípios norteadores das práticas sociais e com a 
disputa de hegemonia presente na ação social. A luta cotidiana repõe de modo constante a necessidade de formulação teórica relacionada com uma estratégia de transformação social. Assim, as disputas em relação aos significados da política de conveniamento remontam tanto à heterogeneidade constitutiva da sociedade civil quanto à dos projetos políticos que as orientam. Há, no movimento, a defesa de perspectivas que reforçam elementos do projeto democrático-popular originário, porém já transformado em um novo projeto, resultante da disputa com o que lhe é antagônico. Por isso, há necessidade de avançar na análise dos significados que autonomia, cidadania e participação assumem para os movimentos populares, e a relação com a conjuntura em que estão inseridos.

\section{Convênios e disputa política nos governos Lula e Dilma}

Com a ascensão de forças políticas na conformação de um novo bloco no poder no país pela eleição para o Governo Federal de Lula (PT: 2003-2010) e Dilma (PT: 2011-2016), houve grande expansão dos convênios estabelecidos pela UNAS com poder público, além do fortalecimento de trabalhos organizativos de caráter mais movimentista. Diante disso, é preciso avançar na definição da cena política dos anos 2000, sobretudo no que se refere às características das forças e projetos em disputa.

A hegemonia neoliberal consolidou o deslocamento operado ao longo dos anos 1980, no plano ideológico, do significado do Estado na vida social, econômica e política do País. A desconstrução do referencial desenvolvimentista antepôs, permanentemente, a ideia de um mercado "autorregulado" a um Estado que deveria ser reformado, no sentido da redução de seu "intervencionismo". Aqui, houve um duplo movimento em favor do avanço das forças neoliberais: operar as bases ideológicas para a desregulamentação do setor financeiro, garantindo maior abertura para entrada e 
saída de capitais do País e, concomitantemente, combater, em favor do mercado, a efetivação de direitos por políticas públicas executadas pelo Estado. A justificativa ideológica apelava para o discurso da "eliminação de privilégios" de trabalhadores, supostamente garantidos por um Estado que obstaculizaria a ação livre do mercado com um protecionismo excessivo.

Tal hegemonia foi conformada pela aliança entre burguesias financeiras e "classes gerenciais", termo que se refere ao "papel da remuneração do trabalho na formação das altas rendas" no neoliberalismo, sendo este um "importante fator de concentração de renda no topo da pirâmide durante as décadas neoliberais" (Duménil e Levy, 2014, pp. 83-92). As organizações que compõem o chamado "terceiro setor" têm em suas direções justamente a "classe gerencial", e a partir dos interesses específicos dessa condição compõem politicamente forças defensoras da transferência da execução de 166 políticas públicas do Estado para a iniciativa privada. Não à toa, Leonardo ressalta que, na política de convênios em habitação, "quem ganha mesmo é a assessoria, os arquitetos de classe média”, valendo-se do termo "classe média” para se referir às camadas superiores de renda entre os assalariados.

$\mathrm{Na}$ "reforma do Estado" implementada pelos governos FHC (PSDB: 1995-2002), um dos principais objetivos colocados era estabelecer novos parâmetros para a participação do mercado na oferta de serviços financiados pelo Estado. A reforma previu a divisão dos órgãos administrativos em setores participantes dos processos de execução de políticas públicas, dentre os quais os serviços não exclusivos, que instituem a propriedade pública não estatal na oferta de serviços subsidiados pelo Estado (Brandão, 2013).

A nova organização institucional liberou o mercado de "obstáculos que o impediam de funcionar como organizador da vida em sociedade", de modo que as classes sociais representadas pelas forças neoliberais encontraram 
melhores condições estruturais para disputar, na sociedade, os rumos da política social necessária para cumprir com aquilo que estava previsto na Constituição em termos de efetivação de direitos. "O primado do mercado, enquanto eixo organizador da economia, é visto como devendo se estender ao conjunto da sociedade". Com isso, opera-se um deslocamento no significado de "sociedade civil" pelo avanço neoliberal ante o projeto democrático-popular: o termo passa a se referir a um conjunto específico de organizações, aquelas "com capacidade para assumir com eficiência a execução das políticas públicas" (Dagnino, Olvera e Panfichi, 2006, pp. 55-56), sendo esta capacidade definida por critérios técnicos, administrativos e financeiros adotados pelo mercado, em contraposição aos movimentos populares em ações diretas e diferentes formas de protesto.

Também nos governos Lula e Dilma houve expansão dos "serviços não exclusivos" do Estado por formas como o convênio. Um dos pressupostos norteadores dessa política é a descentralização administrativa, pela criação de um espaço público composto por entidades de diferentes tipos: religiosas, comunitárias e movimento popular, que possuem a prerrogativa de fiscalizar, induzir e controlar o processo de elaboração e execução de uma política pública.

Já em âmbito municipal, o "modo petista de governar" previu conveniamento de entidades de base comunitária para oferta de serviços públicos: no Orçamento Participativo de Porto Alegre, por exemplo, em diferentes momentos houve a definição da educação infantil como prioridade e, consequentemente, entidades da sociedade civil indicaram instituições a serem conveniadas com a Secretaria Municipal de Educação para contemplar a demanda apresentada. "Em 1993, foram conveniadas as primeiras 40 creches. Em 1994, foram 60 creches. De 1995 até 1999, a partir de política definida pelo OP, foram conveniadas dez creches a cada ano". Em 2003, a cidade chegou a um total de 129 creches (Susin, 
2005, p. 45), e o número subiu para 176 em 2009 (Susin e Peroni, 2011).

Além da dinâmica local, houve efeitos indutores do conveniamento pela conjuntura nacional. No governo FHC, com a restrição do financiamento da educação ao ensino fundamental, recaiu sobre os municípios a garantia orçamentária do ensino infantil. Isso levou a um progressivo aumento da pressão de movimentos populares sobre as prefeituras para provisão de serviços de educação e assistência social. "As associações defensoras dos direitos dos moradores de bairros de baixa renda de Porto Alegre se organizaram para reivindicar solução ao problema social criado pelo governo federal" (Susin e Peroni, 2011, p. 190).

Ressalta-se aqui algo a ser considerado na análise da política nacional e diferenciação entre os governos FHC e Lula-Dilma. O projeto neoliberal tem como elemento central a hegemonia da esfera financeira, traduzida pelo 168 direcionamento da ação e orçamento estatais para remuneração dos setores rentistas (Duménil e Levy, 2014). Uma das formas desse direcionamento é pela redução do "gasto público", ou seja, dos investimentos em políticas sociais como saúde, educação e assistência social, combinado com a adoção de uma política fiscal que se vale de tais recursos para remunerar o mercado financeiro. Por isso, um marco da política neoliberal de FHC, enquanto ministro da Fazenda, foi a criação, em 1994, do Fundo de Estabilização Fiscal (FEF), que durou até o final de 1999, e permitia "ao governo federal manejar livremente cerca de $20 \%$ do orçamento, geralmente retirados de programas sociais, como saúde e educação, e do repasse de verbas para Estados e municípios", direcionando-os para a remuneração dos serviços da dívida pública (Brandão, 2013, p. 114).

Esse cenário teve inflexões com a vitória do PT nas eleições presidenciais de 2002. Os interesses conflitivos e antagônicos no interior do bloco no poder resultaram em uma 
política macroeconômica de redirecionamento dos recursos estatais que beneficiou interesses de setores da burguesia e das classes trabalhadoras. No que se refere à política fiscal, o governo adotou uma política "expansionista" que logrou reduzir a dívida líquida do setor público de $60 \%$ do PIB, no final de 2002, para $35 \%$ em 2012. Atrelado a isso, houve uma expansão do investimento social em diferentes áreas, dentre elas a educação (Barbosa, 2013, p. 92), uma inflexão que contrariou os interesses das forças políticas neoliberais e explica o aumento na oferta educacional e de convênios entre poder público e organizações da sociedade civil.

Nos mandatos de Lula (2003-2010), além de programas como o Universidade para Todos (ProUni), foram implementados: o Fundo de Desenvolvimento e Manutenção da Educação Básica e de Valorização dos Profissionais da Educação (Fundeb), em 2007, que estabeleceu um novo formato de distribuição de recursos federais na educação, incluindo Ensino Infantil na destinação de recursos federais; piso salarial para os professores da educação básica; regras "mais favoráveis aos estudantes para o Fundo de Financiamento ao Estudante do Ensino Superior (Fies)"; o Plano de Desenvolvimento da Educação (PDE); e o Compromisso Todos Pela Educação, que recebeu o mesmo nome "de uma organização da sociedade civil conduzida em sua maioria por empresários e fundações empresariais". A parceria entre Estado e sociedade civil, sobretudo organizações que compõem o terceiro setor e empresariado, era componente central do PDE, que também garantiu o "fim da Desvinculação das Receitas da União (DRU) em relação aos recursos da educação" em 2010. Com essas medidas, o "orçamento do Ministério da Educação passou de cerca de $\mathrm{R} \$ 18$ bilhões em 2002 para cerca de $\mathrm{R} \$ 49$ bilhões em 2010” (Abreu, 2010, pp. 135-140).

No que se refere especificamente à educação infantil, a confluência das medidas voltadas à educação básica 
favoreceu a ampliação de oferta de vagas pelos municípios por conveniamento entre Poder Público e sociedade civil, sobretudo em razão das regras previstas pelo Fundeb. A distribuição de recursos prevê, de acordo com a lei que institui o fundo, repasses para: i) creche pública em tempo integral, na razão de 1,10 ; ii) creche pública em tempo parcial, 0,80 ; iii) creche conveniada em tempo integral, 0,95; e iv) creche conveniada em tempo parcial, 0,80 (Brasil, 2007 , Art. $36, \S 2^{\circ}$ ). "O fator 1,00 equivale ao valor aluno/ ano matriculado nas séries iniciais do ensino fundamental urbano (segmento mais expressivo, em quantitativo de alunos da educação básica)", de modo que 1,10 significa "que o valor por aluno/ano matriculado na creche pública de tempo integral é $10 \%$ superior ao valor do aluno matriculado nas séries iniciais do ensino fundamental urbano", sendo a mesma lógica observada para os demais valores listados (Brasil, 2009, p. 22).

Assim, o Fundeb incluiu "as creches conveniadas no conjunto de instituições subvencionadas”, permitindo repasse para organizações de caráter comunitário, filantrópico ou confessional. A justificativa que fundamentou a política era de que, àquele momento, já havia "inúmeros convênios mantidos pelas prefeituras com tais instituições" (Domiciano, 2009, p. 54). Apesar de o valor do repasse federal por creche conveniada ser menor que o previsto para a pública-estatal, o custo do atendimento pela administração direta é proporcionalmente maior, de modo que se pode afirmar haver uma indução do conveniamento na relação entre Governo Federal e municípios (Pinto, 2007; Domiciano, 2009; Subtil, 2012). A tabela e o gráfico abaixo trazem o aumento no financiamento federal na educação e no número de matrículas em creches decorrentes dessa política: 
Tabela 2

Matrícula na Educação Infantil por etapa no Brasil / Gráfico 1: Total de recursos Fundef e Fundeb 2000-2013 em R\$ bilhões

\begin{tabular}{|l|c|c|c|}
\hline \multirow{2}{*}{ Ano } & \multicolumn{3}{|c|}{ Matrícula na Educação Infantil por etapa } \\
\cline { 2 - 4 } & Total & Creche & Pré-escola \\
\hline 2000 & 5.338 .196 & 916.864 & 4.421 .332 \\
\hline 2002 & 6.130 .358 & 1.152 .511 & 4.977 .847 \\
\hline 2004 & 6.903 .762 & 1.348 .237 & 5.555 .525 \\
\hline 2006 & 7.016 .095 & 1.427 .942 & 5.588 .153 \\
\hline 2008 & 6.719 .261 & 1.751 .736 & 4.967 .525 \\
\hline 2009 & 6.762 .631 & 1.896 .363 & 4.866 .268 \\
\hline 2010 & 6.756 .698 & 2.064 .653 & 4.692 .045 \\
\hline 2011 & 6.980 .052 & 2.298 .707 & 4.681 .345 \\
\hline 2012 & 7.295 .512 & 2.540 .791 & 4.754 .721 \\
\hline 2013 & 7.590 .600 & 2.730 .119 & 4.860 .481 \\
\hline
\end{tabular}

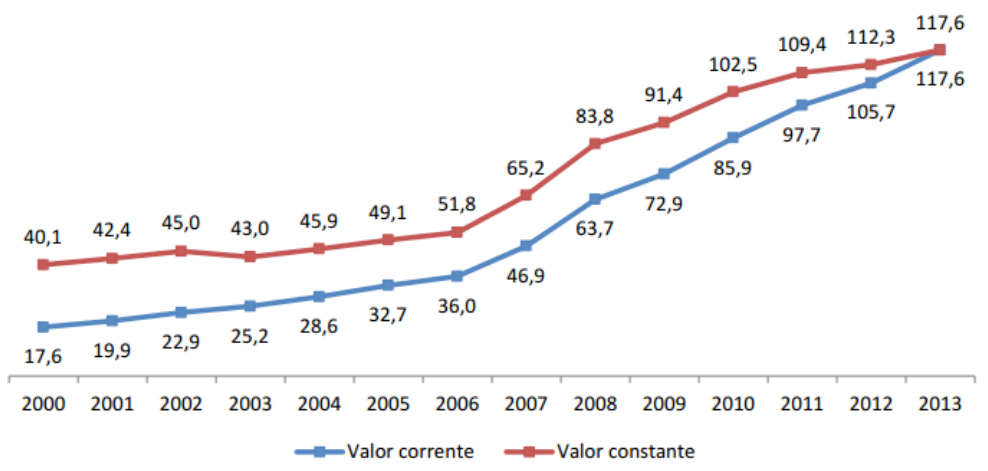

Fonte: Relatório Educação Para Todos no Brasil 2000-2015 (Brasil, 2015)

Não à toa, a UNAS estabeleceu seu primeiro convênio para CEI em 2001, com São Paulo sob gestão de Marta Suplicy (PT: 2001-2004) e o número se expandiu até 2016, nas gestões Serra (PSDB), Kassab (DEM/PSD) e Haddad (PT), quando atingiu 16 CEIs, como mostrado na Tabela 1. Trata-se de uma política ofertada e efetivada em âmbito municipal, mas que remonta a medidas nacionais que elevaram em mais de $100 \%$ as matrículas e os recursos federais 
investidos, com salto a partir do ano de 2007, quando da adoção do Fundeb.

Assim, a cena política nacional nos anos de governos petistas, no que se refere à educação, coloca à análise um paradoxo para definição de sua orientação: de um lado, promoveu significativo aumento da participação privada na efetivação do direito, o que remonta ao projeto neoliberal para a área social; de outro, promoveu significativo aumento orçamentário e da participação do Estado na efetivação do direito, o que contraria o combate do neoliberalismo ao chamado "gasto público" e sua defesa da destinação de recursos orçamentários para os serviços da dívida. Uma política que inverte a tendência anterior de destinação de recursos para os setores financistas, direcionando-os para efetivação de direitos, contraria interesses neoliberais. Assim, as ações governamentais respondem a interesses diferentes daqueles contemplados pelas forças hegemônicas nos anos 1990, 172 e o crescimento no número de convênios em Heliópolis remonta diretamente a essa mudança conjuntural nacional. No entanto, dizer isso não significa que a política esteve diretamente orientada pelas forças democrático-populares, e avançar nessa precisão da análise é fundamental.

O aumento da participação privada na oferta do ensino no país traz consigo uma contradição: a transferência de recursos do Estado para a sociedade civil obedece a lógicas distintas, que variam conforme a correlação de forças e o programa educacional em questão. Nesse mesmo âmbito está a transferência de recursos para um movimento popular que os conquista em um processo de luta por creche, em articulações por espaços como um conselho de Orçamento Participativo, bem como o repasse para empresas. A maioria das análises (Susin, 2005; Susin e Peroni, 2011; Pinto, 2007; Domiciano, 2009; e Subtil, 2012) desconsidera tais paradoxos, e se limita, na definição do significado das políticas, a adotar um único parâmetro: execução por órgão estatal. 
Este seria o elemento definidor do projeto político a que remonta um programa governamental: se a política não for executada pelo Estado, é neoliberal. O limite deste tipo de análise está em desconsiderar muitos dos elementos presentes tanto no neoliberalismo quanto nos demais projetos políticos em disputa. Para superá-lo, é necessário definir as forças políticas em cena, em torno de quais projetos atuam, e de quais modos as disputas entre elas configuram determinada conjuntura.

No que se refere especificamente à UNAS, trata-se de uma força organizada historicamente em torno do projeto democrático-popular, composta socialmente pelas classes populares, e que encontra no convênio significado duplo: atendimento da demanda, com consequente efetivação de seu objetivo social, e fortalecimento político pela ampliação de sua influência no território. O convênio é parte do processo de construção de força política pela UNAS, que integra o campo de forças que deu base de sustentação aos governos Lula-Dilma.

No entanto, a composição das forças democrático-populares também é heterogênea em seu interior, e no que se refere à efetivação de direitos carrega antagonismos entre as classes populares e as classes médias. Ambas são forças sociais que compuseram historicamente o campo democrático-popular, mas que possuem interesses distintos e, algumas vezes, contraditórios entre si. Nos anos 1980, participaram do processo de conformação das forças políticas orientadas pelo projeto democrático-popular tanto os movimentos populares urbanos quanto o movimento sindical, que teve na Central Única dos Trabalhadores (CUT) sua principal ferramenta de articulação e luta. Fez parte do processo de consolidação da CUT o sindicalismo do setor público, que seguiu fortalecido nos anos 1990-2000.

Trata-se de um sindicalismo que se move por interesses e concepções diferentes dos do trabalhador manual que 
compõe a "classe operária" e as classes populares (Boito Jr., 2004, p. 212-213). Uma das questões que opõem interesses entre esse sindicalismo de classe média e os movimentos populares urbanos na conformação do projeto democrático-popular se refere ao lugar do funcionalismo público na efetivação de direitos que ambos defendem. De um lado, o sindicalismo do setor público a reivindica pela ampliação de serviços sob gestão estatal, por meio da construção de carreiras públicas e realização de concursos. De outro, movimentos populares como a UNAS reivindicam, como forma de efetivação do direito e da participação, o repasse de recursos públicos na forma convênio. Esse antagonismo varia de intensidade de acordo com a área de atuação: na habitação, com a produção de moradia por autogestão, uma prática adotada desde o governo municipal de Luiza Erundina (PTSP), o conflito é menor, pois o trabalho envolvido é manual, não entra em contradição com a ideologia que move as clas174 ses médias na defesa da administração direta estatal; em contraposição, na educação, trabalho que ideologicamente se fundamenta no mérito, o embate se explicita, e opõe na cena aqueles que defendem sua estruturação pela seleção estatal meritocrática - oferta estatal de serviços, com seleção do funcionalismo pelo concurso público -, e os que reivindicam o reconhecimento político da participação popular na elaboração e efetivação do direito - oferta de serviços públicos pelo convênio entre Estado e sociedade civil.

Ressalta-se aqui a expressão da "confluência perversa" não apenas nos embates entre forças neoliberais e democrático-populares, mas também no interior destas, o que remonta à sua heterogeneidade constitutiva. As referências a participação, cidadania e autonomia a que o campo democrático-popular como um todo recorre - sindicalismo do setor público e movimentos populares - assumem significados distintos nas disputas de ordem redistributiva por recursos estatais. Unificados na luta por direitos e políticas 
públicas, divergem na sua forma de efetivação, de modo que "participar" e "ser cidadão" varia desde o cobrar a execução pelo Estado até o "fazer junto", em um conflito presente, porém obscurecido pelo uso de referências comuns. Tais diferenças, conforme exposto, remontam à composição do campo democrático-popular por frações distintas das classes trabalhadoras, que por sua condição se beneficiam de modos diferentes de acordo com a forma de execução da política: as classes médias têm maior benefício com a realização de concursos públicos; e o mesmo se pode dizer para as classes populares na celebração de convênios.

$\mathrm{Na}$ política aqui analisada, tais interesses distintos se unificam na luta pela destinação de recursos estatais para a educação, em contraposição aos interesses gerais das forças neoliberais que defendem sua destinação para reprodução do capital financeiro. Porém, divergem na forma da efetivação do direito, se pela ação direta estatal, por espaço público participativo ou por organização da sociedade civil. A política dos governos Lula e Dilma buscou acomodar esses distintos interesses, com a adoção de medidas que favorecem tanto a ampliação do setor público na efetivação de direitos quanto a participação de entidades comunitárias como a UNAS. Além disso, as forças que deram sustentação aos governos Lula-Dilma são ainda mais amplas e heterogêneas, de modo que essa mesma política educacional beneficiou empresas e associações filantrópicas e/ou religiosas. Não à toa, o "Compromisso Todos pela Educação" adotou nome que faz referência direta a uma articulação que tem entre seus integrantes empresas e fundações empresariais: o Movimento Todos pela Educação. A expansão da oferta de ensino respondeu também a tais interesses de forças burguesas, que hegemonizam a condução da política educacional como um todo.

Assim, reproduz-se na política setorial educacional o modelo que define o lulismo: os governos petistas fazem uma 
"constante arbitragem”, pairando sobre as forças políticas atuantes, o que "desmobiliza as classes" e evita a "radicalização" da luta política (Singer, 2012, pp. 200-201). Isso se dá pela conformação de uma aliança de classes na execução das políticas, com atuação conjunta de empresariado e classes populares. Nesse processo, o conjunto de interesses, ideias, valores, princípios e programas de ação que conforma o projeto político do movimento popular já é outro: participação, cidadania e sociedade civil estão aqui esvaziadas de conflitos, e progressivamente aquilo que era "embate" se torna "fazer junto".

\section{Considerações finais}

O desafio permanente colocado para a UNAS no processo organizativo está em ter o reconhecimento social de que a conquista do convênio resulta de uma luta coletiva, não de uma dádiva ou do mercado. Porém há uma permanente disputa entre as forças políticas em ação no inte-

176 rior de um mesmo processo de auto-organização. No caso específico da atuação na educação e assistência social em Heliópolis, isso se explicita pela relação estabelecida entre acesso a recursos estatais e fortalecimento político da UNAS, além da mediação exercida pelo movimento, enquanto força política atuante no território, entre as demandas da população e a política conduzida pelos governos.

Ressalta-se que as forças historicamente articuladas em torno do projeto democrático-popular não são hegemônicas nesse processo. Pelo contrário, travam uma disputa em condições desiguais e dependentes em relação às forças hegemônicas, que são aquelas representantes dos interesses das diferentes frações da burguesia. A desigualdade está posta no acesso aos espaços de poder no Estado e nos aparelhos privados de hegemonia, ambos majoritariamente controlados pelas forças burguesas. A dependência está colocada no fato de que, para melhorar sua posição nos espaços de poder, para avançar no controle dos aparelhos privados de hegemonia 
como uma associação comunitária e para ampliar suas conquistas, as forças democrático-populares dependeram dos resultados das disputas políticas entre as diferentes forças burguesas, e de um permanente processo de negociação/ pressão ante um governo que representa esse conjunto heterogêneo de forças em aliança.

Se por um lado as disputas pelos conceitos de cidadania, sociedade civil e participação indicaram a extensão das conquistas do campo democrático-popular, pois as forças neoliberais encontraram na reapropriação de tais conceitos uma forma de enfrentá-los e neutralizá-los (Dagnino, Olvera e Panfichi, 2006), por outro há uma progressiva transformação dos projetos históricos em disputa. A necessidade permanente de "tapar buraco" e "conceituar", dentro de um processo organizativo e de luta, está inserida em um contexto em que classes populares estão submetidas a formas de dominação clientelistas, autoritárias e de mercado, impostas como mecanismos de integração social e exercício de poder pela força hegemônica.

A inflexão macroeconômica, que contrariou os interesses das forças neoliberais pela alocação de recursos em setores produtivos e no desenvolvimento social, representou para as políticas setoriais de educação e assistência social uma reprodução da lógica neoliberal de transferência de recursos estatais para sua execução pela iniciativa privada. No entanto, essa mesma transferência de recursos atendeu a interesses antagônicos, de forças de mercado que se beneficiam das múltiplas formas de apropriação do público pelo privado, e de forças de base comunitária em luta por políticas públicas e participação. Essa dinâmica repôs, no interior das forças democrático-populares, a disputa entre setores que reivindicam a efetivação do direito pela ampliação de serviços sob gestão estatal, e movimentos populares que reivindicam, como forma de efetivação do direito e da 
participação, o repasse de recursos públicos para entidades que representem seus interesses.

Na política de conveniamento, as diferenças de projeto se explicitam, no plano ideológico, pelos fatores de legitimação da reivindicação do acesso a recursos públicos mobilizados nos discursos. Entre as forças democrático-populares, a legitimação do acesso a recursos e participação na efetivação da política reside na inserção política no território, representatividade em relação às forças sociais que o compõem e à luta histórica por autonomia, participação e cidadania. A categoria a que recorrem como fonte de legitimação da reivindicação é a do direito, e será reafirmada na disputa pela condução da política governamental. Já as forças políticas representantes das burguesias do setor travam a disputa ideológica pela afirmação da lógica de mercado como fonte de legitimação. Nos governos petistas, essas duas perspectivas caminharam em aliança, porém não juntas: o rompimento político posterior explicitou a condição de dependência e desigualdade a que as classes populares estavam submetidas, e os limites que o modelo de arbitragem impôs às conquistas.

\section{Hugo Fanton Ribeiro da Silva}

Pós-doutorando em Ciência Política na Faculdade de Filosofia, Letras e Ciências Humanas da Universidade de São Paulo (FFLCH-USP), com pesquisa sobre relações entre movimentos sociais, empresariado e poder público. Doutor em Ciência Política pelo Instituto de Filosofia e Ciências Humanas da Universidade Estadual de Campinas (IFCH/ Unicamp) e mestre em Saúde Pública pela Faculdade de Saúde Pública da Universidade de São Paulo (FSP/USP2011). Desenvolve pesquisas nas áreas de movimentos sociais, políticas públicas, democracia, comportamento político empresarial, participação social e saúde coletiva. 


\section{Bibliografia}

ABREU, Maria Aparecida Azevedo. 2010. Educação: um novo patamar institucional. Novos Estudos, n. 87, pp. 131-143.

BARBOSA, Nelson. 2013. Dez anos de política econômica. In: SADER, Emir (prg.). Lula e Dilma: dez anos de governos pós-neoliberais no Brasil. São Paulo: Boitempo.

BOITO JR. Armando. 2004. Classe Média e sindicalismo. Primeira Versão. Campinas: IFCH/Unicamp, n. 123.

BRANDÃO, Rafael Vaz da Motta. 2013. Ajuste neoliberal no Brasil. 391f. Tese de Doutorado em História. Niterói: ICHF/UFF.

BRASIL. Lei 11.494/2007. 2007. Regulamenta o Fundo de Manutenção e Desenvolvimento da Educação Básica e de Valorização dos Profissionais da Educação - FUNDEB, Brasília. . 2009. Orientações sobre convênios entre secretarias municipais de educação e instituições comunitárias, confessionais ou filantrópicas sem fins lucrativos para a oferta de educação infantil. Brasília: MEC/SEB. . 2015. Relatório Educação para Todos no Brasil 2000-2015. Brasília: MEC, 2009.

BRESSER-PEREIRA, Luiz Carlos. 2010. Prefácio. In: LOUREIRO, Maria Rita Garcia; ABRUCIO, Fernando Luiz; PACHECO, Regina Silvia. Burocracia e política no Brasil. Rio de Janeiro: Editora FGV.

COBRA, Patricia Lemos Nogueira. 2007. Dinâmica do mercado imobiliário informal da favela de Heliópolis/São João Clímaco. Trabalho de Conclusão de Curso em Arquitetura e Urbanismo. São Paulo: FAU/USP.

DAGNINO, Evelina. 2004. Sociedade civil, participação e cidadania: de que estamos falando. In: BENESSAIEH, Afef; MATO, Daniel (eds.) Politicas de Ciudadanía y Sociedad Civil en tiempos de globalización. Caracas: FaCES, Universidad Central de Venezuela. . 2005. Meanings of Citizenship in Latin America. IDS Working Paper, Brighton, England, n.258, pp. 1-27.

DAGNINO, Evelina; OLVERA, Alberto J.; PANFICHI, Aldo (orgs.) 2006. A disputa pela construção democrática na América Latina. São Paulo: Paz e Terra.

DOMICIANO, Cassia Alessandra. 2009. O Programa "Bolsa Creche” nos municípios paulistas de Piracicaba e Hortolândia. 228f. Dissertação de Mestrado em Educação. Rio Claro: Universidade Estadual Paulista.

DUMÉNIL, Gérard; LEVY, Dominique. 2014. A crise do neoliberalismo. São Paulo: Boitempo.

FELTRAN, Gabriel de Santis. 2008. Fronteiras de tensão: um estudo sobre política e violência nas periferias de São Paulo. Tese de Doutorado em 
Ciências Sociais. Campinas: Instituto de Filosofia e Ciências Humanas da Unicamp.

GEERTZ, Clifford J. 1978. Uma descrição densa: por uma teoria interpretativa da cultura. Rio de Janeiro: Zahar Editora.

MAGNANI, José Guilherme Cantor. 2002. De perto e de dentro: notas para uma etnografia urbana. RBCS, v. 17, n. 49.

NEGRELOS, Eulalia Portela. 1998. Remodelação de bairros populares em São Paulo e Madrid 1976-1992: projeto e participação popular. Dissertação de Mestrado em Arquitetura e Urbanismo. São Paulo: FAU/USP.

PINTO, José Marcelino de Rezende. 2007. A política recente de fundos para o financiamento da educação e seus efeitos no pacto federativo. Educação e Sociedade, v. 28, n. 100, pp. 877-897.

RUQUOY, Danielle. 1997. Situação de entrevista e estratégia do entrevistador. In: ALBARELLO, Luc; DIGNEFFE, Françoise; HIERNAUX, Jean-Pierre; MAROY, Christian; RUQUOY, Danielle; SAINT-GEORGES, Pierre de. Práticas e métodos de investigação em Ciências Sociais. Lisboa: Gradiva, pp. 84-116.

SALES, Teresa. 1994. Raízes da desigualdade social na cultura política brasileira. Revista Brasileira de Ciências Sociais, São Paulo, n. 25, pp. 26-37.

180 SAMPAIO, Maria Ruth Amaral. 1991. Heliópolis: o percurso de uma invasão. Tese de Livre Docência em Arquitetura e Urbanismo. São Paulo: FAU/USP.

SANTOS, Wanderley Guilherme. 1979. Cidadania e justiça. A política social na ordem brasileira. Rio de Janeiro: Campus.

SANTOS, Boaventura de Sousa. 1983. Os conflitos urbanos no Recife: o caso do "Skylab". Revista Crítica de Ciências Sociais, Coimbra, n. 11, pp. 9-60.

SCHERER-WARREN, Ilse. 1993. Redes de movimentos sociais. São Paulo: Edições Loyola.

SINGER, André V. 2012. Os sentidos do lulismo: reforma gradual e pacto conservador. São Paulo: Companhia das Letras.

SUBTIL, Gabriela Franco. 2012. Financiamento e convênios da educação infantil: uma análise a partir de periódicos nacionais. 112f. Trabalho de Conclusão de Licenciatura. Rio Claro: UNESP.

SUSIN, Maria Otilia Kroeff. 2005. A educação infantil em Porto Alegre: um estudo das creches comunitárias. Dissertação de Mestrado em Educação. Porto Alegre: FE-UFRS.

SUSIN, Maria Otilia Kroeff; PERONI, Vera Maria Vidal. 2011. A parceria entre o poder público municipal e as creches comunitárias: a educação infantil em Porto Alegre. RBPAE, v. 27, n.2, pp. 185-201. 


\section{CONTRADIÇÕES E DISPUTAS NA POLÍTICA DE CONVENIAMENTO ENTRE ESTADO E MOVIMENTOS POPULARES NOS ANOS 2000: 0 CASO HELIÓPOLIS}

HUGO FANTON RIBEIRO DA SILVA

Resumo: Este artigo tem por objetivo analisar significados do financiamento público de atividades político-sociais e seu impacto na ação e no projeto político dos movimentos populares, com enfoque na relação entre Estado e sociedade pela forma convênio durante os governos Lula e Dilma. Para atingir os objetivos, foi realizado um estudo de caso em Heliópolis, favela de São Paulo/SP, articulado com sistematização de literatura secundária referente às políticas do setor de educação no nível nacional nos governos petistas. $\mathrm{O}$ conceito de "confluência perversa" foi mobilizado para analisar os significados que os convênios assumem para os movimentos populares, assim como discutir os paradoxos que o acesso a recursos públicos traz para o interior das forças democrático-populares, em posição desigual e dependente em relação a forças neoliberais na cena política brasileira nos anos 2000.

Palavras-chave: Democracia; Movimentos Sociais; Participação; Políticas públicas; Convênio.

\section{CONTRADICTIONS AND DISPUTES IN THE POLICY OF AGREEMENTS BETWEEN THE STATE AND POPULAR MOVEMENTS IN THE 2000S: THE HELIOPOLIS CASE}

Abstract: This article aims to analyze the meanings of the public financing of sociopolitical activities and their impact on the action and political projects of popular movements, focusing on the relation established between State and society through the agreement during the administrations of former presidents Lula and Dilma. To do so, a case study was conducted in Heliopolis, a favela in São 
Paulo (Brazil), articulated with the systematization of secondary literature regarding educational policies at the national level in PT administrations. The concept of "perverse confluence" was employed to analyze the meaning that the agreements assume for popular movements, as well as to discuss the paradoxes that the access to public resources brings to popular-democratic forces, which occupied an unequal and dependent position in relation to neoliberal forces in the Brazilian political scene in the 2000s.

Keywords: Democracy; Social Movements; Participation; Public Policy; Agreement.

Recebido: 04/06/18

Aprovado: 23/10/18 